Article

\title{
Why Don't More Farmers Go Organic? Using A \\ Stakeholder-Informed Exploratory Agent-Based Model to Represent the Dynamics of Farming Practices in the Philippines
}

\section{Laura Schmitt Olabisi ${ }^{1, *}$, Ryan Qi Wang ${ }^{2}$ and Arika Ligmann-Zielinska ${ }^{3}$}

1 Department of Community Sustainability and Environmental Science \& Policy Program, Michigan State University, 151 Natural Resources Building, 480 Wilson Road, East Lansing, MI 48824, USA

2 Department of Civil and Environmental Engineering, Virginia Tech, 113 Patton Hall (0105), Blacksburg, VA 24061, USA; E-Mail: wangqi@vt.edu

3 Department of Geography and Environmental Science \& Policy Program, Michigan State University, Room 121 Geography Building, 673 Auditorium Rd., East Lansing, MI 48824, USA; E-Mail: ligmannz@msu.edu

* Author to whom correspondence should be addressed; E-Mail: schmi420@msu.edu; Tel.: +1-517-432-4128.

Academic Editors: James Millington and John Wainwright

Received: 17 January 2015 / Accepted: 13 October 2015 / Published: 22 October 2015

\begin{abstract}
In spite of a growing interest in organic agriculture; there has been relatively little research on why farmers might choose to adopt organic methods, particularly in the developing world. To address this shortcoming, we developed an exploratory agent-based model depicting Philippine smallholder farmer decisions to implement organic techniques in rice paddy systems. Our modeling exercise was novel in its combination of three characteristics: first, agent rules were based on focus group data collected in the system of study. Second, a social network structure was built into the model. Third, we utilized variance-based sensitivity analysis to quantify model outcome variability, identify influential drivers, and suggest ways in which further modeling efforts could be focused and simplified. The model results indicated an upper limit on the number of farmers adopting organic methods. The speed of information spread through the social network; crop yields; and the size of a farmer's plot were highly influential in determining agents' adoption rates. The results of this stylized model indicate that rates of organic farming adoption are highly sensitive to the yield drop after switchover to organic techniques, and to the speed of
\end{abstract}


information spread through existing social networks. Further research and model development should focus on these system characteristics.

Keywords: organic agriculture; agent-based modeling; sensitivity analysis; social networks; Philippines

\section{Introduction}

Acreage under organic farming methods is increasing globally, as government support for organic farmers and market demand for organic products grows [1]. A major driving force behind both of these trends is the recognition of the negative impacts of chemically-intensive farming methods on the environment and human health [2,3]. Approximately one-third of global land under organic production is located in the developing world [1]. In many developing nations, agricultural production is dominated by smallholder farmers, who often lack access to crop insurance or inexpensive credit. Some have argued that organic agriculture can benefit smallholder farmers by eliminating their reliance on expensive, fossil fuel-derived chemical inputs [4]. Organic farming therefore could make smallholder farmers more resilient to input price shocks, which are a significant source of insecurity for them [5]. This argument is bolstered by research from the United States, which indicates that organic farmers spend less on inputs than conventional farmers [6]. Policy makers, extension agents, and non-governmental organizations that serve developing-world farmers need a clear understanding of farmers' motivations and challenges in converting to organic agriculture, so that efforts to promote organic farming will be maximally effective.

Few organic adoption studies to date have portrayed a dynamic and complex decision environment, rather than a static snapshot of farmer decision-making [7]. Farmers' demographic characteristics, their economic motivations, their concern for the environment and for their families' health, all interact in complex and heterogeneous ways as they consider their options and choose their production method. Moreover, farmers' choices may be different year to year, depending on the decision context. They may choose to convert to organic, and then return to conventional methods when their situation changes. Most previous studies have not taken advantage of modeling tools that could portray this type of decision-making in dynamic contexts, such as agent-based modeling (ABM).

$\mathrm{ABM}$ has been used extensively in studying land-use conversion decisions, and has provided insights into how decision/environment feedback loops operate to produce non-intuitive outcomes [8-15]. Another advantage of ABM is its ability to represent the dynamics of social influences and information propagation through social networks via peer-to-peer, or "word-of-mouth", communications [16,17]. Previous studies have found that a farmer's source of information about farming and organic techniques influences his or her decision to adopt organic methods [18]. Peer-to-peer sharing through social networks can be an important source of information for farmers [19]. Modeling the spread of information about organic agricultural techniques through social networks could therefore provide insight into how best to promote these technologies and support farmer adoption.

$\mathrm{ABM}$ has been successfully applied to agricultural systems all over the world [20-22], to study the complex interactions between farmers, global and regional crop markets, and biophysical (especially hydrological and crop-soil) systems $[8,13,20,23,24]$. Agricultural applications vary from new practice 
adoption [8,14,20,24-27], changes in agricultural production and its viability [14,25,28], the impact of different decision making practices on agricultural land use/land cover change [14,23,25,28], evaluation of landscape structure [13,28], farmers' imitative behavior [8,29], and explicit analysis of agricultural policies $[8,20,30]$. For example, Berger [8] uses the concept of innovation diffusion to study various farming production alternatives and their influence on local hydrology in Chile. Happe et al. [30] present an ABM for agricultural policy analysis of different farm structures in Germany, Schreinemachers et al. [31] build an ABM to analyze the diffusion of greenhouse agriculture in Thailand, and Evans et al. [25] develop an empirically-rich ABM to explore the transition from shifting cultivation to rubber production in Laos. Many researches stress the usefulness of ABM to represent the diversity of farmer decision-making [13,20,27,30].

Of particular interest to our study are ABM applications that simulate organic farming adoption [26,27]. For example, Kaufmann et al. [27] develop an agent-based model of agricultural decision making that utilizes the theories of planned behavior and innovation diffusion, coupled with a survey-informed social network sub-model, to evaluate the diffusion of organic farming in Latvia and Estonia. The goal of their modeling exercise is to test how the economic changes are intertwined with agent-agent interactions in the formation of beliefs concerning the transition to organic farming. They conclude that mere social influence is not sufficient when modeling conversion from traditional to organic farming. Without exogenous economic factors, in the form of subsidies, "organic farmers remain organic, and conventional farmers remain conventional" (p. 2589). In a comparable study, Deffuant et al. [26] develop an ABM to model organic farming in a selected region of France. The novelty of their approach lies in introducing an auxiliary institution agent that evaluates the farm potential and assists the farmer in the decision to go organic. Similarly to Kaufmann et al. [27], they conclude that organic farming adoption results from complex interactions between economic and social processes.

In this paper, we define $\mathrm{ABM}$ as a simulation environment composed of heterogeneous computational entities (called agents) that represent Philippine smallholder farmers, for the purpose of exploring group dynamics around organic agriculture adoption. The agents are situated in a common agricultural environment of an upland paddy rice system, where organic farming practices are being actively promoted by a local non-governmental organization (NGO). Agents' decision making to adopt and maintain organic agriculture is constrained by limited access to information about the optimal farming strategies and the economic resources available. The agents are driven by their individual goals and social behaviors, and they constantly adapt to changing agro-economic and ecological conditions $[8,12,32]$. Previous agricultural ABM research suggests that, to account for a fuller complexity of farmer decision making and provide room for experimentation aimed at sustainable resource use, agent behavior should be informed by both normative science (economics) and social science that more realistically represents the actual resource-use decision making [33]. Thus, in our model, the socioeconomic micro-decisions of agents, strengthened by the interactions among them, generate macro-structures of the system including the level of organic farming adoption. The goal of this structure is to determine how landscape-scale patterns of adoption emerge from individual farmer decision-making. 


\section{Study Area and Research Questions}

The Philippines, like many countries in the developing world, has passed legislation supporting organic agriculture, citing its benefits to human health and the environment [34]. Acreage under organic agriculture has risen steeply in recent years, from approximately 3500 hectares in 2004 to 52,400 hectares in 2009 [35]. This represents only $0.6 \%$ of the country's 9.2 million hectares of cultivated land area. The Philippine commitment to organic agriculture is nonetheless significant, given the country's history of promoting chemically intensive technologies to raise yields of rice, a staple crop [36]. Achieving self-sufficiency in rice production is another important goal of the Philippine government (the country consistently ranks as one of the top five rice importers) [37]. This necessitates the country increasing rice yields to the levels of some of its more productive Asian neighbors [38]. Achieving both higher rice yields and greater amounts of land under organic production will require investments in programs that target smallholder farmers, who constitute the majority of rice producers in the Philippines.

We chose Negros Island, in the central Philippines, as a study site (Figure 1). The island is located in the country's agricultural belt; major crops include sugarcane, maize, rice and coconut. While the rice-growing areas just north of Manila are known as the country's rice bowl, rice lands on Negros are also highly productive, according to the Philippine Bureau of Agricultural Statistics (www.bas.gov.ph); three harvests per year are standard.

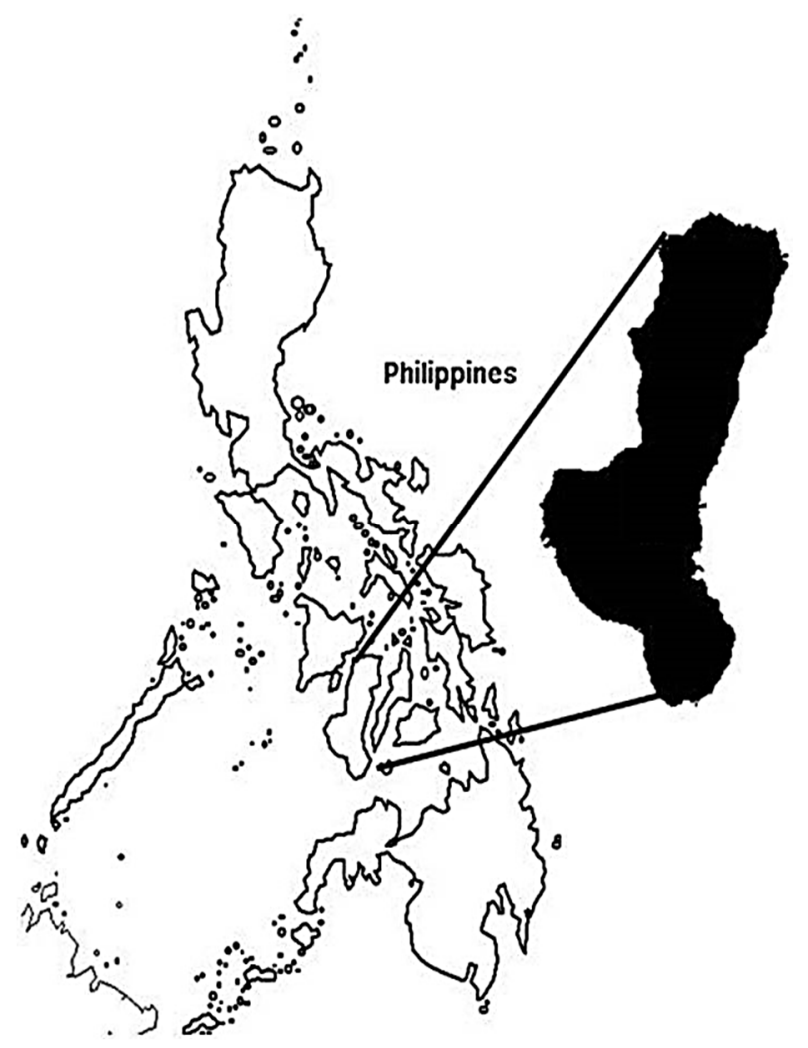

Figure 1. Map of the Philippines showing location of Negros Island where the farmer focus groups were conducted in an upland rice-growing area. 
The Negros Institute for Rural Development (NIRD) is an internationally funded and locally governed NGO, which has been promoting organic agricultural techniques in an upland rice producing area on Negros since 1999. The municipality of Canlaon, where NIRD is located, is therefore an ideal location for studying the spread of organic technology adoption. According to NIRD staff, some farmers in the area have adopted organic techniques and used them consistently, while a larger number of farmers converted to organic methods but then went back to conventional methods after some time. This presents an intriguing research question which we addressed in our model: Why do some farmers on Negros go organic, while others do not? Put another way, what are the driving factors determining the rate of organic adoption over time which Negros has experienced?

\section{Data Collection}

\section{Focus Group Discussions and Model Parameterization}

We collected both qualitative and quantitative data from the study site to parameterize the model. We organized focus groups in November, 2010, to assess the state of organic agriculture adoption in the Canlaon region, and to identify barriers to adoption. Because NIRD introduced organic methods to this region and conducts periodic workshops and trainings in organic techniques, they are in contact with most of the organic farmers in the area. Ten farmers who had practiced organic methods for at least the past three years were able to attend the focus group sessions, and we constructed groups of similar size to represent conventional farmers (eight participants) and farmers who had tried organic farming but had returned to conventional methods (ten participants). Organic farmers were over-represented in this sample compared to their presence on the landscape, because the purpose of the focus group exercise was to examine the motivations and decision processes of farmers who choose to go organic.

The groups were asked to discuss the questions: (1) Why do you farm using your chosen method (organic/conventional)? (2) What are the benefits of using your chosen farming method? and (3) What are the challenges of using your chosen farming method? A note-taker was present in each group to record key concepts as the discussions took place. Afterward, the three groups were brought together in a common forum to share their observations and ask one another questions. These sessions were recorded and coded using three categories (Farm Characteristics, Organic Adoption, and Challenges) and fifteen sub-categories (farm size; family size; years farming; general history (any information about the farm not covered under other categories); markets (where farm products are sold); off-farm income; livestock; fertilizer use; history using organic; perceived benefits of organic; characteristics of organic (aspects of organic technologies that farmers discussed, other than benefits); pest management; yield; knowledge of organic; labor). All conversations took place in Cebuano-Visayan, the local language. The model decision structure represented in Figure 2 was developed to reflect, as closely as possible, the decision-making process around organic conversion described to us by farmers. Both organic and conventional farmers agreed on the importance of an "experimentation" period for organic conversion, in which they would grow organically on one portion of land to test the efficacy of this method. In addition, all farmers agreed that, in order to farm organically, one has to know how to use organic methods and be able to bear the initial cost of changeover from conventional to organic methods. 


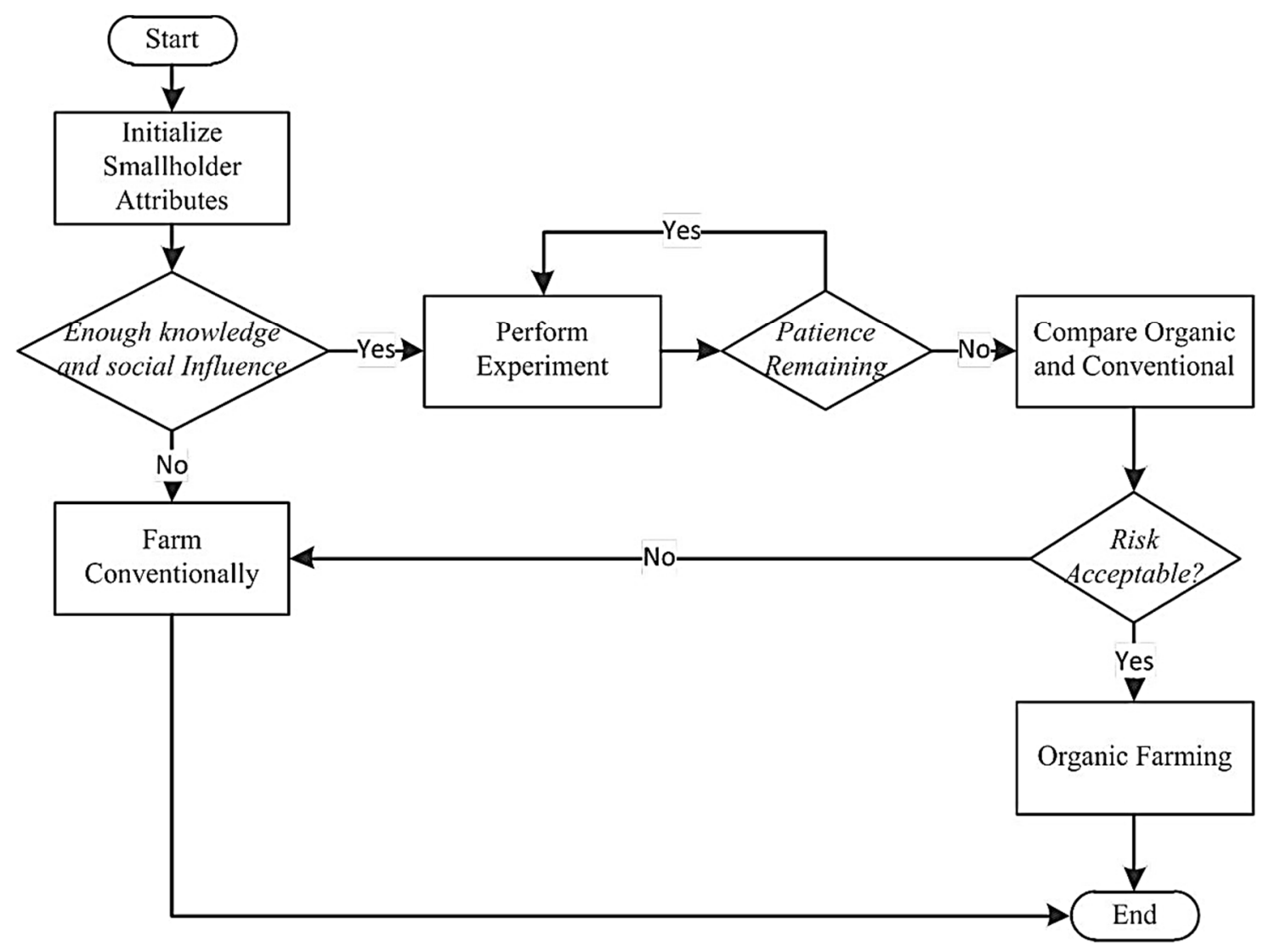

Figure 2. The decision-making process used by farmer agents in the agent-based modeling (ABM). In order to experiment with organic agriculture (plant half of their land using organic methods), farmers must have knowledge of organic techniques. Once they begin an experiment with organic techniques, they wait a certain number of rice seasons to compare their yields under organic production with their yields under conventional production. The number of seasons they are willing to wait is designated by "patience", a characteristic of each farmer agent that describes his/her dedication to organic production. After the finished experiment, they evaluate both methods while considering the risk imposed by external climatic and economic conditions. Then they chose which method to adopt.

From June 2010 through December 2010 (the length of one cropping season), NIRD field staff assisted the authors in collecting information on crop yields and farm size from the farmers who participated in the focus groups. A total of twenty-eight farmers participated in this data collection (ten organic farmers, eight conventional farmers, and ten mixed-method farmers). "Mixed-method" refers to farmers who at some point have tried organic farming, but do not do so consistently and may have reverted to conventional farming at the time of data collection. This sample was not intended to be statistically representative for the larger population of rice farmers; rather, the information was to be used to develop the farm characteristics represented in the model.

The average farm size of the participants was 0.9 hectares ( 0.63 ha for the organic group; 0.85 ha for the conventional group, and 1.1 ha for the mixed-methods group). This is smaller than the 2.8 ha average farm size for the island [39]. Given the highly unequal distribution of farm acreage between large-scale sugarcane plantations and smallholder rice and vegetable farms on Negros Island, the average farm size of the study participants represents the landholdings of small-scale farmers [40]. The average yield for 
one cropping season reported by the organic group was 3.0 MT/ha; for the conventional farmers it was 5.4 MT/ha; and for the mixed-methods farmers it was 4.5 MT/ha. We believe the organic yields were lower for two reasons: first, some of the organic farmers reported that access to organic fertilizers was a problem, and they may not have been adding adequate levels of nutrients to ensure yields. Secondly, some of the farmers who converted to organic methods in the recent past may have been suffering from the initial yield loss at changeover (see below for more information). However, we would caution against using one cropping season's data from a limited sample of farmers to depict an overall pattern. For this reason, we used a wider yield distribution drawn from regional datasets to parameterize our model simulation.

Among organic farmers who participated in the focus group, concern for the environment and for their family's health were agreed to be key reasons for choosing organic methods. Participants also noted that organic methods reduce input costs and therefore improve net profit. In addition, ducks and fish can be integrated into paddy rice production when organic methods are used, while chemical herbicides and pesticides are harmful to these animals. The incorporation of animal agriculture/aquaculture with rice production was clearly seen as desirable by organic farmers, who mentioned the enhanced productivity that this integration affords, and the weed and pest-controlling characteristics of ducks. These observations are consistent with literature studies of paddy rice agriculture elsewhere in Asia [41]. Price premium for organic rice was not a determinant in the choice of organic methods for focus group participants, because the farmers do not have access to customers who might be willing to pay a premium.

Farmers who used conventional techniques, or who had switched between organic and conventional techniques, were not as strongly devoted to their method of production as the organic farmers. In fact, most of the farmers in these groups stated that they try to incorporate some organic techniques, such as mixing animal manure with chemical fertilizer, or using organic pest control methods. The most significant barriers to organic farming mentioned were labor requirements (mainly for composting and weeding), lack of nutrient inputs (particularly for farmers without animals), and lack of information about organic techniques. Some conventional farmers, but not all, believed that high-yielding varieties of rice (HYVs) were preferable to traditional varieties for their consistent high yields, and these HYVs require chemical pest control. Farmers also stated that they are sometimes forced to use chemical inputs by creditors, who view these inputs as necessary to guarantee their return on investment. Although we didn't explicitly model this requirement as part of the simulation, we noted that without access to credit, most farmers would not be able to produce. This statement is therefore well worth further examination in the context of promoting organic agriculture.

\section{Methods}

\subsection{Agent-Based Model}

The ABM simulates a virtual farming area containing 2500 farmer agents who must choose between organic and conventional farming methods over the course of 100 cropping seasons (approximately 33 years). We chose the number 2500 because this is a reasonable approximation of the number of rice farmers that live in the Canlaon region; this number therefore represents the "upper limit" of organic diffusion, if all farmers were to adopt organic technologies [39]. Each farmer agent represents a farm 
household, and all agents operate in a virtual "social space" (a concept which is relevant for the social network learning described below), but the model is not spatially explicit. We built the model using Repast Simphony software and programmed it using Java language. The farmer agents all have the same decision-making rule (see Figure 2), but since their attributes are different, their decision outcomes are also different. This decision-making framework was developed based on the focus group discussions, and reflects the considerations of the farmers as described in the groups.

\subsubsection{Farmer Agent Specification}

The literature on organic farming adoption indicates that economic benefits can be a significant driver in farmers' decisions to convert to organic methods [42]. Several studies have also pointed to farmer characteristics that influence whether farmers choose to convert to organic methods. These include age, gender and education of the producer [18,43]; farmers' social and ecological values [44,45]; sources of information about farming [18]; and, possibly, the desire to become more resilient to input price shocks or climatic shocks [46]. All of these empirical observations were used during agent conceptualization of our $\mathrm{ABM}$ of organic farming, together with the focus group results.

The agents were assigned values for land area, animal ownership, and number of people in the household (corresponding to household food demand and labor availability), taken from the range of observed values for these variables in the field and in Philippine agricultural statistics, and assuming a uniform distribution across the range [47] (See Table 1 for range of values assigned to agent characteristics; more details about the model and its parameterization can be found in Supplementary Section 1). We used uniform distributions for all our input variables because the small sample of participants that served as the source of input to our agent attributes was insufficient to generate more complex empirical probability density functions. The rationale behind this distribution is that it requires at most two parameters (i.e., upper/lower bounds) identified from data. Initial capital assets were also randomly distributed across a uniform range, but after the start of model simulation capital assets were calculated for each time step based on yield.

We constructed a stylized social network for the farmer agents to represent the ways in which farmers influence their social connections and share information about organic techniques. The structure of the network was informed by qualitative data (i.e., how farmers described receiving information). The farmer agents were assigned values for "social reach", the unitless maximum distance between nodes which, in this case, were connected farmers (i.e., the extent of influence). Any two farmers within each other's social reach were connected by a link. Each link creates a dyad and each farmer in the dyad is a social connection to the other. These links were the channels through which the model passed information about organic methods; farmers could not experiment with organic techniques unless they were connected to a farmer who already used them. The links represent the farmer's social influence on his/her networks. The values of social reach were initially set at 5 , and then drawn from a uniform distribution during our computational experiment of sensitivity analysis, because we did not collect information on the structure of the social network at the field site [48]. 
Table 1. Factors (parameters) used in the model with their respective probability distributions (U—continuous uniform, D—discrete uniform).

\begin{tabular}{ccc}
\hline Input Factor & Definition and Units & Distribution \\
\hline Area of land (a) & Hectares & $\mathrm{U}=(0.25,10)$ \\
Labor availability (la) & People in household & $\mathrm{D}=\{1,2,3, \ldots, 8\}$ \\
Social reach (sr) & Distance in agent's social space (unitless) & $\mathrm{U}=(5,25)$ \\
Social influence (si) & Density of social connections among agents & $\mathrm{D}=\{1,2,3, \ldots, 30\}$ \\
Animal ownership (ao) & Proportion of farmers owning animals (unitless) & $\mathrm{U}=(0,1)$ \\
Patience (p) & Number of farming seasons (3 seasons/year) & $\mathrm{D}=\{1,2,3, \ldots, 15\}$ \\
Risk taken (r) & Attitude towards risk related with & $\mathrm{U}=(0,1)$ \\
Cost of conventional fertilizer (ccf) & the adoption of organic farming (unitless) & $\mathrm{U}=(40,400)$ \\
Cost of organic fertilizer (cof) & Philippine Pesos per kilo & $\mathrm{U}=(40,400)$ \\
Average cost of other conventional input (coci) & Philippine pesos per kilo & $\mathrm{U}=(3000,7500)$ \\
Average cost of other organic input (cooi) & Philippine pesos per hectare & $\mathrm{U}=(1100,2900)$ \\
Average cost of labor (cl) & Philippine pesos per hectare & $\mathrm{U}=(6000,13,000)$ \\
Average price of rice (p) & Philippine pesos & $\mathrm{U}=(7.44,17.86)$ \\
Average yield (y) & Philippine pesos per kilo & $\mathrm{U}=(1200,6000)$ \\
Organic fertilizer threshold (oft) & Kilos per hectare & $\mathrm{U}=(0,10)$ \\
Land area for one labor (lal) & Hectares & $\mathrm{U}=(0.1,10)$ \\
\hline
\end{tabular}

Farmer agents were initially randomly distributed in unitless social space. To initialize the model, we set up the network structure by applying Hamil and Gilbert's methods [48]. A virtual grid space is created with the dimension of $100 \times 100$. Therefore, the space is divided into 10,000 grid cells. Then 2500 agents are created, and each of them occupies a cell. Each cell can only contain one agent. The values of the social attributes are initialized following the distributions mentioned above. After the attributes are set, agents are connected based on the values of social reach. Any two agents $\boldsymbol{a}$ and $\boldsymbol{b}$ are connected if Equation (1) is satisfied.

$$
\begin{aligned}
\operatorname{distance}(\boldsymbol{a}, \boldsymbol{b}) & =\sqrt{\left(x_{a}-x_{b}\right)^{2}+\left(y_{a}-y_{b}\right)^{2}} \\
\leq & \min (\operatorname{social} \text { reach }(\boldsymbol{a}), \operatorname{social} \text { reach }(\boldsymbol{b}))
\end{aligned}
$$

The model was "seeded" with between 5 and 10 organic farmer agents. This is representative of the pioneer smallholder farmers in the Canlaon region who learned organic farming through NIRD when the NGO first was established there. Figure 3 depicts the social network for one model run.

Farmer agents were also assigned a value for the attribute "patience", and a value for "risk attitude". The patience attribute represented the number of rice cropping seasons a farmer was willing to experiment with organic methods before comparing his or her net profit under organic farming with net profit under conventional methods. "Patience" therefore represented all of the values a farmer might hold that might prompt him or her to consider organic farming, even if it was not initially as productive as conventional farming. 


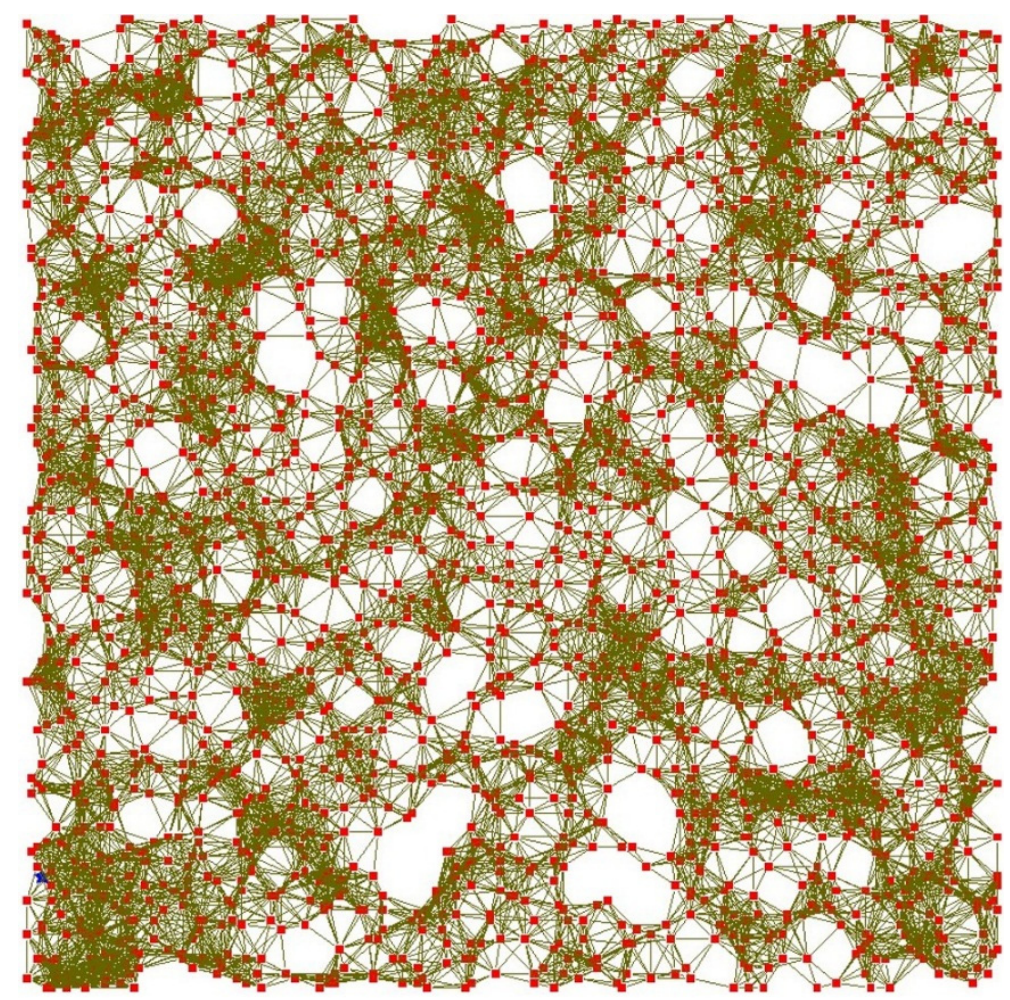

Figure 3. Social network depicted at the end of a model run with the "social reach" variable set at 20. The agents are distributed randomly in social space; circles represent farmer agents, and lines represent social connections between the farmer agents.

"Risk attitude" was an index assigned to each farmer agent reflecting their willingness to try a new farming method after their field experiment (in this case, organic farming). This index varied between 0 and 1 for each agent, and was compared to a randomly generated "risk index" between 0 and 1 for each farming season, representing the time-dependent environmental riskiness of trying a new technology (encompassing, for example, weather and economic conditions, political instability, etc.). Notice that "risk attitude" was only used to determine which farming method to choose when a given farmer agent expected profit from both organic farming and conventional farming. If a farmer had a relatively low risk attitude, indicating he/she was risk taking, he/she would be willing to try new technologies when expected profits were both positive. Conversely, if a farmer had a relatively high risk attitude, indicating risk aversion, he/she would almost never be willing to try organic farming. The qualitative and quantitative evidence from the field support this depiction of conversion to organic methods as a significant risk. Studies suggest an initial yield loss associated with organic conversion, which represents a risk to a farmer's income stream and household food supply [4].

\subsubsection{Decision Algorithm}

Before the start of each time step, a farmer agent must decide whether to experiment with organic farming (Figure 2). This can only take place if the farmer is connected to other farmer agents with adequate knowledge of organic techniques. The model assumes that this knowledge is disseminated through the social network, so if a farmer agent is connected to a certain number of organic farmers or farmers experimenting with organic techniques, he/she is able to begin an experiment. We assumed the 
number, which is called "influence threshold", could be drawn from a discrete uniform distribution between 1 and 8 , representing a minimum and maximum number of people a farmer might reasonably turn to for farming advice. Once the condition was satisfied, the farmer agent would begin his/her experiment. This means that he/she plants half of his/her land using the organic techniques and half using the conventional techniques.

Input costs were calculated for each farmer agent using a given farming technique at each model time step. These costs included the cost of fertilizer, the cost of other inputs, and the cost of labor (if labor provided by the household was not sufficient). To simulate the fluctuation of input costs across the model run time, the amount in Philippine pesos assigned to labor, fertilizer and input costs for a given time step was drawn randomly from a uniform distribution based on data collected in the field and from the Philippine Bureau of Agricultural Statistics (see Table 1). Conventional farmers must purchase all of their fertilizer, but organic farmers may derive some of their fertilizer from composting agricultural waste (such as manure and rice straw), and purchase organic fertilizer for their remaining needs. We assumed that farmers with at least one hectare of land and one animal were able to produce all of their fertilizer on-farm, up to 10 hectares (this threshold was based on empirical observations, and tested with the sensitivity analysis described below). The amount of fertilizer applied was assumed to be up to 1.5 times the average nitrogen application for the region recorded in 2010 agricultural statistics (organic and conventional fertilizer types are adjusted by their respective nitrogen contents), based on what the farmer-agent could afford.

Yield was calculated as a function of the nitrogen application for either conventional or organic methods, using a Michaelis-Menten equation applied to rice yields and fertilizer application rates from provincial statistics:

$$
\begin{aligned}
& \text { yield }=\left(\text { land area } \times 1.0045^{\text {seasoncount }} \times 4800\right. \\
& \times \text { fertilizer amount }) /(\text { fertilizer }+6.1)
\end{aligned}
$$

where fertilizer amount is the maximum nitrogen application rate a farmer can afford, and seasoncount is the model time step [49]. Data from the region indicate that conventionally grown rice yields increase at a rate of $0.45 \%$ per season, and this annual increase was simulated in the model. When a farmer agent switched their land to organic methods (or planted half of their land in organic methods as an experiment), the modeled yield initially dropped by $50 \%$ before recovering at a rate of $5 \%$ per season to the yields described by the Michaelis-Menten equation above. Therefore, after approximately 10 seasons (or three years), yields for a farmer who had converted to organic methods would be no different than if he/she had continued to farm conventionally. This initial yield drop represents a high estimate of initial yield losses reported in field experiments by organic farmers, due to the need for soil organic matter and soil chemistry to recover post-chemical fertilizer application [4].

A farm household consumes part of the rice (enough to feed the household members during the cropping season) and sells the remainder, if any. The price of rice was also drawn randomly from a uniform distribution based on recent farmgate prices reported by the Bureau of Agricultural Statistics (see Table 1). The sale of the rice provides the capital input necessary for the rice season that follows. It is important to note that organic rice is sold at the same price as conventionally grown rice in our modeled environment, because farmers in the Canlaon region do not have access to markets at which organic rice might fetch a premium due to transportation constraints. 
As mentioned above, each farmer agent was randomly assigned a value for the variable "patience", which represents the length of the experiment he/she conducts before comparing the net profit from conventional farming methods to the net profit from organic farming methods and choosing the method that is more profitable. In the model, this number ranged from one to 15 farming seasons (based on the farmer focus groups, we thought five years would be the maximum amount of time a farmer would experiment with an organic technology). The more "patience" an agent has, the more likely he/she is to choose organic farming, because once the yields have recovered from the initial loss caused by switching to organic methods, input costs tend to be lower for organic farmers, who can produce inputs on-farm rather than buying them.

Based on the presented specification, our model can be placed somewhere on the continuum between the highly abstract agricultural ABM that result in stylized simulations [29] and empirically-rich ABM equipped with microeconomic mechanisms and complex agricultural markets [20,30]. This mixed approach, combining observational and simulated data in computational experimentation, has been successfully applied in other agricultural ABM [14,23].

\subsection{Exploring Model Outcome Variability with Sensitivity Analysis}

Sensitivity analysis of agricultural ABM is rarely undertaken. Notable examples include Happe et al. [30] and Schouten et al. [50] where regression-based metamodels are developed to evaluate the influence of the uncertain model inputs on outputs. In their study, Schouten et al. [50] also employ a simple one-parameter-at-a-time (OAT) sensitivity analysis and compare it with the regression metamodel.

The ABM described above is an example of a dynamic model that emulates a complex agricultural system. It is, therefore, imperative to apply a simulation procedure appropriate to complex nonlinear models, which would account for input and output variability as well as the potential input interactions. Neither regression nor OAT meet these requirements. Crosetto et al. [51], Gomez-Delgado and Tarantola [52], Chu-Agor et al. [53], and Ligmann-Zielinska et al. [11] among others, postulate the use of Monte Carlo simulation that incorporates global sensitivity analysis (GSA) as a part of computational experiments. GSA is a method of experimentation in which the variability of model results is quantified based on simultaneous sampling of the whole set of input variables, which are then examined individually and in combinations [54].

The most comprehensive method of GSA is based on model-independent output variance decomposition, in which model outcome variability (represented using variance V) is apportioned to various model inputs [54,55], so that the underlying causes of variable outcomes can be explicitly identified. The procedure starts from generating $M$ samples of input variable values using a selected experimental design. The model is then executed for each sample $m \in M$ and the result is recorded. These output values form a distribution which can be summarized using descriptive statistics like mean and variance $(\mathrm{V})$. GSA then uses output variance decomposition which partitions $\mathrm{V}$ based on the contribution of each input variable to $\mathrm{V}$. This partitioning (aka decomposition) is accomplished by estimating the conditional variances of every input variable $\mathrm{k}$. By calculating the ratio of conditional variance due to $\mathrm{k}$ to the total $\mathrm{V}$, we obtain a first order sensitivity index (Sk). If a given variable $\mathrm{k}$ has a relatively high value of $\mathrm{Sk}$, its single influence on output variability is substantial. To express the interactions among variables, which are ubiquitous in complex system models, we also compute a total 
effect index for every k (STk), which accounts for all higher-order effects of inputs [56]. Consequently, variables with relatively low values of the $(\mathrm{Sk}, \mathrm{STk})$ pairs are deemed unimportant in shaping output variability and, in the consecutive experiments, can be set to constant values contributing to model simplification. In addition, the (Sk,STk) pairs provide valuable information on the mechanisms that affect the dynamics of the model and, consequently, can serve as quantitative indicators explaining model drivers. For details on (Sk,STk) calculation the reader is referred to Saltelli et al. [54].

To calculate the (Sk,STk) pairs we employed the quasi-random Sobol experimental design described in Saltelli (2002), which proved to be the most effective in approximating the values of sensitivity indices [57]. To compute the indices, we used SimLab open source software (http://ipsc.jrc.ec.europa.eu/?id=756).

\subsection{Computational Experiments}

Following the quasi-random experimental design mentioned above, we employed Monte Carlo simulation and executed the model $\mathrm{M}$ times, where $\mathrm{M}$ was set to 17,408 runs based on the procedure described in Ligmann-Zielinska and Sun [58]. At the end of each simulation, we recorded the number of agents who adopted organic farming $(\mathrm{N})$ and compared that to the total number of farmers $(\mathrm{T})$ in the model using a simple ratio N/T, referred to as RATIO in the following sections. Given that the focus of our experimentation is organic farming adoption, we set the number of farmers to 2500 (i.e., $\mathrm{T}=2500$ ), with a time step of one cropping season, and ran the model for 100 seasons. The results were analyzed in two ways. First, we compiled the RATIO values into a probability distribution and summarized it using descriptive statistics (including average and variance). Second, we performed variance decomposition of the RATIO distribution, and calculated Sk and STk for each of the 16 input variables (a total of 32 indices plus an interaction index) to investigate the overall model behavior and determine its critical drivers. The interpretation of the pairs of indices (Sk, STk) followed the procedure described in Ligmann-Zielinska and Sun [58].

\section{Results}

Agent-Based Model

By the end of the model simulation, all farmer agents had the opportunity to experiment with organic techniques, as the knowledge of organic agriculture spread throughout the social network. Experimentation concluded by rice season 23, at which point all farmer agents selected a farming type. The number of organic adopters in the model leveled out after experimentation in the model run using default parameter values (Table 1, Supplementary Section 1) (Figure 4). This ratio of organic farmers to total farmers was robust to the seasonal variation in labor, fertilizer, and input prices, as well as modelsimulated seasonal variation in yields, as indicated by the fact that after the initial decision period, the ratio of organic to total farmers did not change significantly. This result is qualitatively similar to the patterns of adoption reported to us by the NGO operating in the Canlaon region, and by the farmers who participated in the focus group. Both NGO workers and farmers confirmed that, after an initial period when many farmers seemed to be adopting organic methods, the adoption rate leveled off and most farmers did not switch to organic despite learning about organic methods. This observation is similar to the conclusion derived from the study by Deffuant et al. [26] which suggests that, while sympathetic to 
organic agriculture, farmers did not convert to organic even though they were exposed to positive messages from the public.

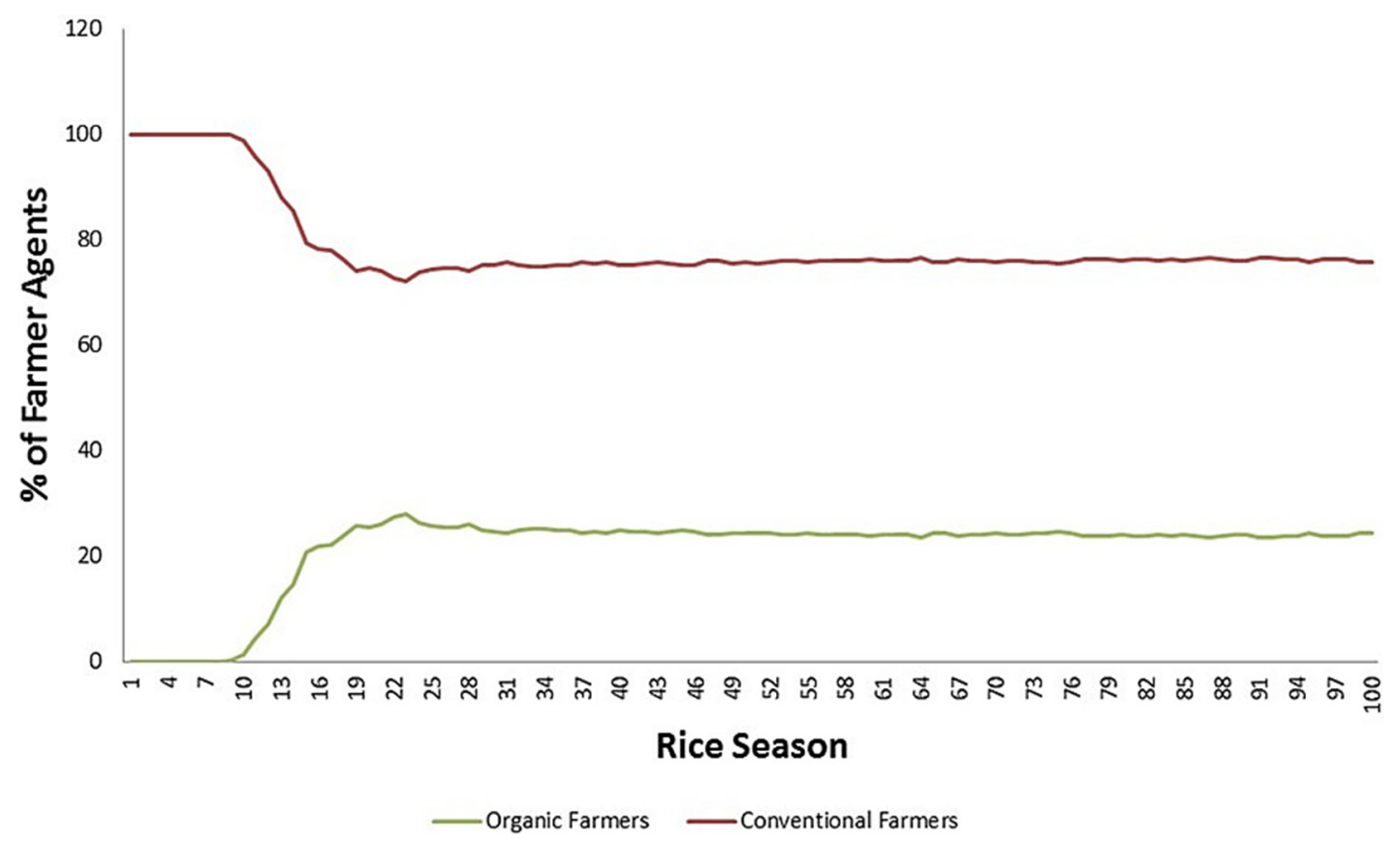

Figure 4. Model output depicted number of organic farmers and number of conventional farmers over the 100 cropping seasons simulated in the model, at default parameter values (see supplementary for description).

The box plot in Figure 5 summarizes the distribution of RATIO. The Monte Carlo simulations result in RATIO ranging from $0 \%$ adoption of organic farming to the maximum of $60 \%$ organic farming adoption. The mean adoption of organic farming equals $31 \%$ of the total agent population, with a substantial level of variability $(\mathrm{std}=33 \%)$, which we analyze in the following section.

Sensitivity Analysis: Variance Decomposition of Model Results

The results of variance decomposition of the ratio of organic farmers to total farmer agents (RATIO) are depicted in Figure 6. As mentioned above, model sensitivity to different inputs is analyzed separately for their individual influence (Sk) and their total (STk) influence. With the first order sensitivity index (Sk) we look for important input variables that, if fixed independently, would reduce the variance of RATIO the most. In other words, the variables with relatively high $\mathrm{S}$ values have the most impact on the variability of the adoption of organic farming. In our experimentation, the social reach (defined in Section 4.1.1) scores highest ( $\mathrm{Ssr}=20 \%$ of total variance), followed by yield $(\mathrm{Sy}=15 \%)$, and area of land under cultivation $(\mathrm{Sa}=12 \%)$. 


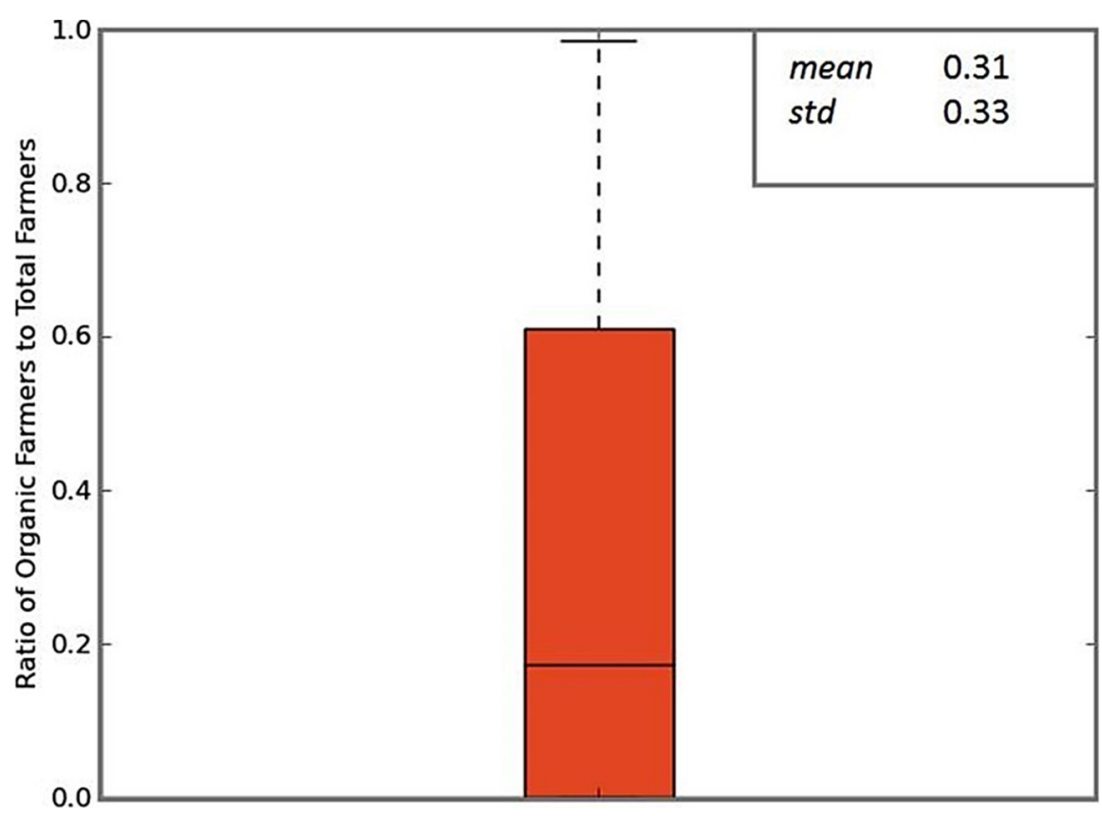

Figure 5. Distribution of the ratio of organic farmer agents to total farmer agents at the end of the model run (100 cropping seasons), over all Monte Carlo sensitivity simulations. This ratio ranges from $0 \%$ of farmer agents adopting organic methods to a maximum of $60 \%$ of farmer agents adopting organic methods, with a mean adoption rate of $31 \%$.

\section{First Order Index Sk}
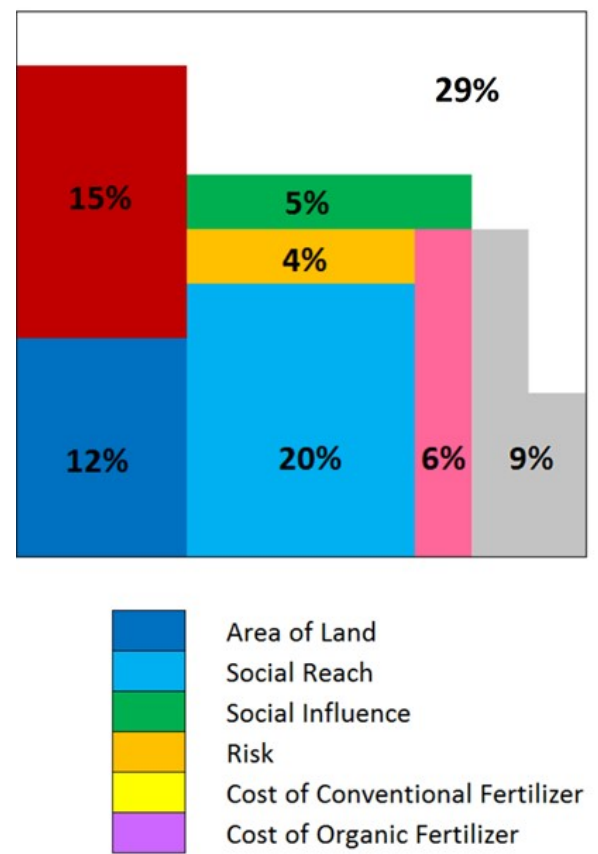

Area of Land

Social Reach

Social Influence

Risk

Cost of Conventional Fertilizer

Cost of Organic Fertilizer

\section{Total Effect Index STk}
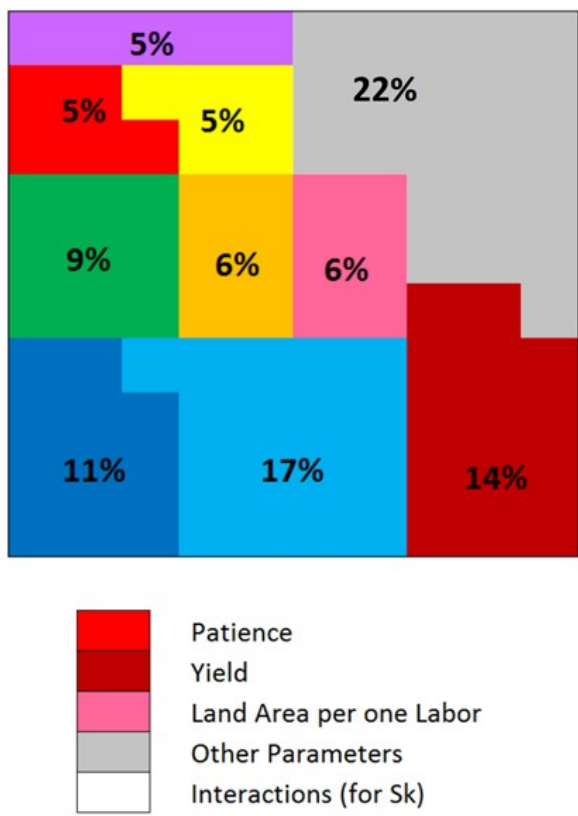

Patience

Yield

Land Area per one Labor

Other Parameters

Interactions (for Sk)

Figure 6. Variance decomposition of variable effects on model output (ratio of organic-adopting farmer agents to total farmer agents). Model sensitivity to different input variables is analyzed separately for their first order influence (Sk) and their total effects (STk) influence, in which variable interactions are explicitly quantified. The variables with relatively high $\mathrm{S}$ values have the most impact on the variability of the proportion of farmer agents who adopt organic methods. 
The model's nonlinear behavior is expressed by the relatively high level of variable interactivity, which is derived from the percentage sum of all first order indices. In our simulation, this sum amounts to $71 \%$ of RATIO variability (Figure 6 ). Therefore, only $71 \%$ of the variance in organic farming adoption rates can be explained by analyzing the variables in isolation. The remaining $29 \%$ of $\mathrm{V}$ is attributed to variable interdependence, which is expressed using the total effect index (STk).

Over half of the variables ( 9 out of 16) contribute substantially to the complex behavior of the model. The highest interaction effect can be observed for social reach $(\mathrm{STsr}=17 \%)$, yield $(\mathrm{STy}=14 \%)$, area of farmland $(\mathrm{STa}=11 \%)$, and influence threshold i.e., the density of social connections of any given agent (STsi $=9 \%$ ). Consequently, not only do these four variables individually contribute to the variability of the RATIO, but they also have a strong influence when analyzed as a group.

Other variables that somewhat contribute to RATIO variability include the cost of fertilizer (both conventional, where STccf $=5 \%$, and organic, where STcof $=5 \%$ ), labor availability (STlal $=6 \%$ ), attitude to risk taking $(\mathrm{STr}=6 \%)$, and patience $(\mathrm{STp}=6 \%)$.

\section{Discussion}

There appears to be an upper limit on the number of farmers choosing to go organic that is fairly robust to fluctuations in prices and the external risk environment. The results of the sensitivity analysis, which reveal how influential the various model variables are in determining the ratio of organic adopting farmers to total farmers, gives us insight into why this limit exists. The sensitivity analysis suggests that the decision to shift from traditional to organic farming is mainly driven by yield, and by imitative behavior, that is, by the number of farmer agents that have already adopted organic farming, as indicated by the strong effects of social reach and influence threshold on the organic adoption ratio (Figure 6). Consequently, our ABM is a classic example of simulating innovation diffusion, where the decision made by agent (A) is influenced by the decisions of proximal agents in A's social space [59-61]. The fact that social reach and influence threshold account for $26 \%$ of output variance corroborates our postulate about the role of diffusion of innovation in explaining organic farming adoption in our ABM.

Particularly, social reach and influence threshold affect the rate at which farmers "learn" about organic farming, a prerequisite to their experimentation with organic technologies. This is important in the model context because of the assumption that conventional yields rise over time. The more rice cropping seasons that go by before a farmer agent learns about organic technologies and is able to experiment with them, the higher the baseline conventional yields to which he/she compares organic yields - therefore, the less likely it is that he/she will choose to switch to organic. When yields are higher, the loss of $50 \%$ of yield during switchover is a greater absolute yield loss compared to when yields are lower. For example, if conventional yields are one ton/ha, upon switchover organic yields would be 0.5 ton/ha. Given the lower costs of organic farming, the farmer might be able to make up this 0.5 ton/ha difference between organic and conventional yields in net profit by going organic. However, if yields are 5 tons/ha, the yield loss upon switchover would be 2.5 tons/ha- a greater profit gap to make up.

We can also conclude that the adoption decision is dependent on the land area an agent farms. Land area constraints on organic farming adoption were discussed in the farmer focus groups, and the model's sensitivity to this variable confirms that farmers with limited land may not be able to generate the nutrients they need to use as inputs for organic production. However, the model was not sensitive to the 
"organic threshold", or the amount of land required to produce on-farm organic fertilizer. This provides evidence for rejecting our hypothesis that only farmers who can produce their own fertilizer on-farm will be able to use organic methods. Interestingly, none of the variables that would seem to have a direct influence on the variability of organic farming (like cost of organic fertilizer and cost of other organic inputs) drive the switch from conventional to organic farming, suggesting that cost comparisons between farming methods may not comprise a farmer's main motivation for adopting organic.

Patience and fertilizer costs play particularly intriguing roles in determining organic adoption rates. When treated independently, these variables have negligible influence on the adoption of organic farming (their Sk values equal zero). However, their influence becomes much more pronounced when analyzed in interactions with other variables, suggesting that they play a complex intertwined role in the decision to switch cultivation to organic farming. This suggests that value orientations towards promoting family health and health of the environment, which were prominent topics of discussion in the focus groups, do not by themselves determine whether a given farmer will choose to adopt organic methods. Rather, knowledge of organic methods and the ability to produce organic fertilizer may be pre-requisites for a farmer putting his or her pro-health or pro-environment values into action. Farmers who have not been able to practice organic methods may nonetheless be interested in integrated pest management techniques, and this was a major topic of discussion in the focus group sessions [62].

Based on the sensitivity analysis we can also suggest the direction of ABM simplification. In particular, animal ownership, labor availability, crop price, labor costs, the amount of land needed to produce organic fertilizer on-farm (organic threshold) and other organic and conventional costs proved to be unimportant in shaping the variability of the RATIO statistics. Consequently, an equivalent simplified model would have these variables set to constant average values, reducing the dimensionality of the model from 16 to 9 uncertain inputs. This simplified model would be equivalent to its predecessor in that it would maintain the variability of RATIO (i.e., with V unchanged) [11,54]. This property can be of value in policy analysis where a certain level of result variability is required to account for any unanticipated events (surprises) in the target system. At the same time, a model with a smaller number of variables can be easier for stakeholders and decision-makers to understand. The drawback of our model simplification is that it is dependent on the type and form of the output variable. Every time we substitute RATIO with a different output of interest (e.g., we introduce different categories of organic farmers based on their land management practices or household income), we should revisit the initial ABM formulation and perform a separate variance-based model simplification.

\section{Implications and Limitations}

Quantitative data on organic adoption over time, which would allow for more extensive validation of the model, is not yet available from this region. However, these model results are consistent with anecdotal observations collected by NIRD and expert opinion of in-region farmers - for example, the NGO has observed that, despite a long-term presence in the region, the number of farmers who have decided to convert to organic methods remains limited. Similarly, the model depicted nearly all farmers experimenting with organic methods after encountering these methods through their social network, but only a minority of the farmer agents ended the model run by adopting organic. This confirms the 
model's usefulness as a scoping exercise that can shed light on where future research and farmer support activities should be focused.

We can suggest that further research would be warranted into the social network among farmers in this region, and farmers' means of sharing information, since social reach and influence threshold were both found to be significant in determining rates of organic adoption. Our model simulation used a uniform, random social network to represent information sharing, which obviously does not reflect the network topology in a typical community [27]. Moreover, there is no feedback effect from farmers observing organic experiments which have been abandoned - it is possible that if a significant number of these occurred in their social network, they might be more reluctant to try organic agriculture in the first place. However, it is worth noting that this dynamic was not mentioned in the focus groups as a factor in determining organic experimentation.

An interesting implication of the model output seems to be that, as conventional yields rise due to improved crop varieties and other variables, at some point it may be "too late" for farmers to consider going organic, because conventional yields would be high enough that the $50 \%$ loss occasioned by organic switchover would represent too large of a yield gap for the farmer. The significance of the yield variable in determining organic adoption rates confirms this interpretation of the model. Therefore, if organic adoption is desirable in a given area, informing interested farmers about organic techniques relatively quickly (possibly through strategic use of social networks), while minimizing the initial yield losses from switching to organic methods and boosting organic yields as quickly as possible to compete with conventional yields (for example, through intensive soil fertility amendments), would seem to be the best set of strategies. To return to the original research question proposed by our NGO partner NIRD, we seem to have identified two major drivers of organic adoption: yield and information sharing through social networks. Additional research on how these variables change over time should help to confirm this determination.

We did not collect detailed demographic data on the farmers who participated in the focus groups, which limited the degree to which we were able to assess how organic adoption rates may differ by gender, age, years spent farming, etc. It is likely that these demographic variables also affect the nature of the social networks in which farmers are embedded. The topology of the social networks represented in the model was therefore totally under-developed, and warrants further exploration in a more sophisticated modeling framework. In addition, our data collection was limited to one rice cropping season by the time and budget available for this study. Given that we are simulating a dynamic system, observing empirical trends over multiple seasons would give us more insight into whether the behavior simulated in the model is similar to the behavior of the real-world system. One of the reasons organic adoption is being promoted worldwide is for resilience to climate change-induced drought and other extremes in precipitation and temperature patterns [63]. An improved version of this model would include such shocks, in order to observe their effects on organic adoption and yields compared to conventional yields. In addition, economic shocks such as restriction to credit or large spikes in prices (larger than we modeled here) could shed light on the relative resilience of organic techniques compared to conventional techniques.

Another shortcoming of our model is its lack of spatial information. Clearly, many aspects of farm production are highly dependent on that farm's location in the landscape, and one would expect organic 
adoption to be affected by spatial characteristics such as farm slope, proximity to roads and water sources, soil characteristics, etc. We hope to include spatial aspects in a future version of this model.

Importantly, we were using the ABM as an exploratory, rather than a predictive, model [64,65]. Given the complex and uncertain nature of the simulated upland farming system, and the paucity of data from the region, we believe a traditional quantitative model that seeks to make predictions about systemic outcomes is inappropriate [66]. Rather, our goal was to shed light on the dynamic aspects of the system described in questions 1 and 2 in the introduction, so that we might target future research and modeling efforts. This approach is philosophically different from the traditional use of statistical or optimization techniques to design a "best" model which produces a "right" answer [66], but it is no less powerful. Systems modelers have argued for decades that an optimization approach to a complex system with high levels of uncertainty can lead to incomplete consideration of system drivers at best [67], and misleading or erroneous conclusions at worst [68]. A dynamic simulation of a complex system, as undertaken here, can be used for theory development and hypothesis testing [69]. With more empirical data with which to calibrate and validate the model, however, this model could be used to make more targeted projections to inform policy in a given location.

\section{Conclusions}

We built a stylized agent-based model to explore the reasons behind low adoption rates of organic agriculture in a productive rice-growing region in the upland Philippines, where organic agriculture has been promoted for fourteen years. The model was run for multiple input variable sets that denote different socioeconomic, behavioral, and ecological characteristics of the farmers and the agricultural system. Given the uncertainty of the system, we explored the variability of the results using a variance-based sensitivity analysis framework to identify the core drivers of the decision to adopt organic farming. We found that the speed of information spread through the social network was highly influential in agents' decisions to adopt organic agriculture, because the longer it takes for them to hear about organic techniques and experiment with them, the more progress conventional varieties and techniques achieve in boosting yields, leading to opportunity costs for farmers who convert to organic. Land area is a constraint to organic adoption, because farmers with small fields are not able to generate on-farm organic inputs that are sufficient to maintain yields. The model revealed a high degree of complexity in farmers' decision-making, with interactive effects between decision variables explaining one-third of the variation in organic adoption rates. Yield improvements and information spread through social networks appear to be the major drivers of organic adoption, warranting further research and modeling attention, and perhaps programmatic targeting by our partner NGO. In addition, more research on farmers' decision-making processes is warranted, as these processes are complex and driven by interactions between economic, social and ecological factors. Continued interaction with farmers in the region will allow us to gain more insight into their decision-making environment and constraints.

\section{Acknowledgments}

We thank the Center for Advanced Studies in International Development at Michigan State University, which funded this research, and the Negros Oriental Institute for Rural Development. 


\section{Author Contributions}

Laura Schmitt Olabisi oversaw the overall development of this project and is the lead writer of this paper. Laura Schmitt Olabisi performed the field interviews with stakeholders and processed the data. Ryan Qi Wang was the primary developer of the model and performed its calibration. Ryan Qi Wang is also the lead author of the Methods section and the Supplementary. Laura Schmitt Olabisi and Arika Ligmann-Zielinska conceived and designed the experiments. Ryan Qi Wang performed the experiments. Arika Ligmann-Zielinska performed and wrote the sensitivity analysis sections.

\section{Conflicts of Interest}

The authors declare no conflict of interest.

\section{References}

1. Willer, H., Kilcher, L., Eds. The World of Organic Agriculture: Statistics \& Emerging Trends 2009; International Federation of Organic Agriculture Movements (IFOAM): Bonn, Germany, 2009.

2. Horrigan, L.; Lawrence, R.S.; Walker, P. How sustainable agriculture can address the environmental and human health harms of industrial agriculture. Environ. Health Perspect. 2002, 110, 445-456.

3. Pimentel, D. Green revolution agriculture and chemical hazards. Sci. Total Environ. 1996, 188(S1), S86-S98.

4. Mendoza, T.C. Evaluating the benefits of organic farming in rice agroecosystems in the Philippines. J. Sustain. Agric. 2004, 24, 93-115.

5. Eakin, H. Smallholder maize production and climatic risk: A case study from Mexico. Clim. Change 2000, 45, 19-36.

6. Uematsu, H.; Mishra, A.K. Organic farmers or conventional farmers: Where's the money? Ecol. Econ. 2012, 78, 55-62.

7. Burton, M.; Rigby, D.; Young, T. Modelling the adoption of organic horticultural technology in the UK using duration analysis. Aust. J. Agric. Resour. Econ. 2003, 47, 29-54.

8. Berger, T. Agent-based spatial models applied to agriculture: A simulation tool for technology diffusion, resource use changes and policy analysis. Agric. Econ. 2001, 25, 245-260.

9. Parker, D.C.; Manson, S.M.; Janssen, M.A.; Hoffman, M.J.; Deadman, P. Multi-agent systems for the simulation of land-use and land-cover change: A review. Ann. Assoc. Am. Geogr. 2003, 93, 314-337.

10. An, L.; Linderman, M.; Qi, J.; Shortridge, A.; Liu, J. Exploring complexity in a human-environment system: An agent-based spatial model for multidisciplinary and multiscale integration. Ann. Assoc. Am. Geogr. 2005, 95, 54-79.

11. Ligmann-Zielinska, A.; Kramer, D.B.; Cheruvelil, K.S.; Soranno, P.A. Using uncertainty and sensitivity analyses in socioecological agent-based models to improve their analytical performance and policy relevance. PLOS ONE 2014, 9, e109779. 
12. Acosta-Michlik, L.; Espaldon, V. Assessing vulnerability of selected farming communities in the Philippines based on a behavioural model of agent's adaptation to global environmental change. Glob. Environ. Change 2008, 18, 554-563.

13. Valbuena, D.; Verburg, P.; Veldkamp, A; Bregt, A.K.; Ligtenberg, A. Effects of farmers' decisions on the landscape structure of a Dutch rural region: An agent-based approach. Landsc. Urban Plan. 2010, 97, 98-110.

14. Bert, F.E.; Podesta, G.P.; Rovere, S.L.; Menendez, A.N.; North, M.; Tatara, E.; Laciana, C.E.; Weber, E.; Toranzo, F.R. An agent based model to simulate structural and land use changes in agricultural systems of the argentine pampas. Ecol. Model. 2011, 222, 3486-3499.

15. Huang, Q.; Parker, D.C.; Sun, S.P.; Filatova, T. Effects of agent heterogeneity in the presence of a land-market: A systematic test in an agent-based laboratory. Comput. Environ. Urban Syst. 2013, 41, 188-203.

16. Goldenberg, J.; Libai, B.; Muller, E. Talk of the network: A complex systems look at the underlying process of word-of-mouth. Mark. Lett. 2001, 12, 211-223.

17. Allsop, D.T.; Bassett, B.R.; Hoskins, J.A. Word-of-Mouth research: Principles and applications. J. Advert. Res. 2007, 47, 398-411.

18. Burton, M.; Rigby, D.; Young, T. Analysis of the determinants of adoption of organic horticultural techniques in the UK. J. Agric. Econ. 2008, 50, 47-63.

19. Conley, T.; Udry, C. Social learning through networks: The adoption of new agricultural technologies in Ghana. Am. J. Agric. Econ. 2001, 83, 668-673.

20. Schreinemachers, P.; Berger, T. An agent-based simulation model of human-environment interactions in agricultural systems. Environ. Model. Softw. 2011, 26, 845-859.

21. Matthews, R.B.; Gilbert, N.G.; Roach, A.; Polhill, J.G.; Gotts, N.M. Agent-based land-use models: A review of applications. Landsc. Ecol. 2007, 22, 1447-1459.

22. Kaye-Blake, W.; Li, F.Y.; Martin, A.M.; McDermott, A.; Rains, S.; Sinclair, S.; Kira, A. Multi-Agent Simulation Models in Agriculture: A Review of Their Construction and Uses; Lincoln University: Christchurch, New Zealand, 2010.

23. Bithell, M.; Brasington, J. Coupling agent-based models of subsistence farming with individual-based forest models and dynamic models of water distribution. Environ. Model. Softw. 2009, 24, 173-190.

24. Matthews, R. The People and Landscape Model (PALM): Towards full integration of human decision-making and biophysical simulation models. Ecol. Model. 2006, 194, 329-343.

25. Evans, T.P.; Phanvilay, K.; Fox, J.; Vogler, J. An agent-based model of agricultural innovation, land-cover change and household inequality: The transition from swidden cultivation to rubber plantations in Laos PDR. J. Land Use Sci. 2011, 6, 151-173.

26. Deffuant, G.; Huet, S.; Bousset, J.P.; Henriot, J.; Amon, G.; Weisbuch, G. Agent based simulation of organic farming conversion in Allier département. In Complexity and Ecosystem Management: The Theory and Practice of Multi-Agent Systems; Janssen, M.A., Ed.; Edward Elgar Publishers: Chelten-Ham, UK, 2002; pp. 158-187.

27. Kaufmann, P.; Stagl, S.; Franks, D.W. Simulating the diffusion of organic farming practices in two New EU Member States. Ecol. Econ. 2009, 68, 2580-2593. 
28. Bakker, M.M.; van Doorn, A.M. Farmer-specific relationships between land use change and landscape factors: Introducing agents in empirical land use modelling. Land Use Policy 2009, 26, 809-817.

29. Gotts, N.M.; Polhill, J.G. When and how to imitate your neighbours: Lessons from and for FEARLUS. J. Artif. Soc. Soc. Simul. 2009, 12, 2.

30. Happe, K.; Kellermann, K.; Balmann, A. Agent-based analysis of agricultural policies: An illustration of the agricultural policy simulator AgriPoliS, its adaptation, and behavior. Ecol. Soc. 2006, 11, 49 .

31. Schreinemachers, P.; Berger, T.; Sirijinda, A.; Praneetvatakul, S. The diffusion of greenhouse agriculture in northern Thailand: Combining econometrics and agent-based modeling. Can. J. Agric. Econ. 2009, 57, 513-536.

32. Valbuena, D.; Verburg, P.; Veldkamp, A.; Bregt, A.K.; Ligtenberg, A. An agent-based approach to explore the effect of voluntary mechanisms on land use change: A case in rural Queensland, Australia. J. Environ. Manag. 2010, 91, 2615-2625.

33. Jager, W.; Janssen, M.A.; De Vries, H.J.M.; De Greef, J.; Vlek, C.A.J. Behaviour in commons dilemmas: Homo economicus and Homo psychologicus in an ecological-economic model. Ecol. Econ. 2000, 35, 357-379.

34. Congress of the Philippines. An Act Providing for the Development and Promotion of Organic Agriculture in the Philippines and for Other Purpose, in Republic Act 10068. Fourteenth Congress: Manila, Philippines, 2009.

35. Lesaca, P.R.A. Organic Agriculture in the Philippines: Going Back to Basic. BAR Digest 201213 February 2014. Available online: http://www.bar.gov.ph/organic-agriculture (accessed on 10 January 2015).

36. David, C.C. Agriculture. In The Philippine Economy: Development, Policies, and Challenges; Balisacan, A.M., Hill, H., Eds.; Oxford University Press: New York, NY, USA, 2003; pp. 175-218.

37. National Economic and Development Authority (NEDA). Medium-Term Philippine Development Plan, 2004-2010; NEDA: Manila, Philippines, 2004.

38. Herdt, R.W.; Barker, R.; Rose, B. The Rice Economy of Asia; International Rice Research Institute: Manila, Philippines, 1985; Volume 2.

39. Collado, P.M.G.; Tia, M.E.; del Prado, D.G.L.; Taguibolos, G.B.; Lipio, G.M., Jr. Characteristics of Farm Holdings: Evidence from the Philippines' Census of Agriculture; Southeast Asian Regional Center for Graduate Study and Research in Agriculture: Los Baños, Philippines, 2013.

40. Schmitt, L. Developing and applying a soil erosion model in a data-poor context to an island in the rural Philippines. Environ. Dev. Sustain. 2009, 11, 19-42.

41. Muramoto, J.; Hidaka, K.; Mineta, T. Japan: Finding opportunities in the current crisis. In The Conversion to Sustainable Agriculture: Principles, Processes and Practices; Gliessman, S.R., Rosemeyer, M., Eds.; CRC Press: Boca Raton, FL, USA, 2010; pp. 273-302.

42. Klonsky, K.; Greene, C. Widespread adoption of organic agriculture in the US: Are market-driven policies enough? In Proceedings of the American Agricultural Economics Association Annual Meeting, Providence, RI, USA, 24-27 July 2005.

43. D’Souza, G.; Cyphers, D.; Phipps, T. Factors affecting the adoption of sustainable agricultural practices. Agric. Resour. Econ. Rev. 1993, 221, 59-165. 
44. Best, H. Environmental concern and the adoption of organic agriculture. Soc. Nat. Resour. 2010, 23, 451-468.

45. Mzoughi, N. Farmers adoption of integrated crop protection and organic farming: Do moral and social concerns matter? Ecol. Econ. 2011, 7, 1536-1545.

46. Cauwenbergh, N.V.; Biala, K.; Bielders, C.; Brouckaert, V.; Franchois, L.; Garcia Cidad, V.; Hermy, M.; Mathijs, E.; Muys, B.; Reijnders, J.; et al. SAFE—A hierarchical framework for assessing the sustainability of agricultural systems. Agric. Ecosyst. Environ. 2007, 120, 229-242.

47. Philippine Bureau of Agricultural Statistics. Area Planted/Harvested of Crops; Report 2007; Philippine Bureau of Agricultural Statistics: Manila, Philippines, 2007.

48. Hamill, L.; Gilbert, N. Social circles: A simple structure for agent-based social network models. J. Artif. Soc. Soc. Simul. 2009, 12, 3.

49. Datta, S.K.D. Improving nitrogen fertilizer efficiency in lowland rice in tropical Asia. Fertil. Res. 1986, 91, 71-186.

50. Schouten, M.; Verwaart, T.; Heijman, W. Comparing two sensitivity analysis approaches for two scenarios with a spatially explicit rural agent-based model. Environ. Model. Softw. 2014, 54, 196-210.

51. Crosetto, M.; Tarantola, S.; Saltelli, A. Sensitivity and uncertainty analysis in spatial modelling based on GIS. Agric. Ecosyst. Environ. 2000, 81, 71-79.

52. Gomez-Delgado, M.; Tarantola, S. GLOBAL sensitivity analysis, GIS and multi-criteria evaluation for a sustainable planning of a hazardous waste disposal site in Spain. Int. J. Geogr. Inf. Sci. 2006, 20, 449-466.

53. Chu-Agor, M.L.; Muñoz-Carpena, R.; Kiker, G.; Emanuelsson, A.; Linkov, I. Exploring vulnerability of coastal habitats to sea level rise through global sensitivity and uncertainty analyses. Environ. Model. Softw. 2011, 26, 593-604.

54. Saltelli, A.; Ratto, M.; Andres, T.; Campolongo, F.; Cariboni, J.; Gatelli, D.; Saisana, M.; Tarantola, S. Global Sensitivity Analysis: The Primer; Wiley-Interscience: Chichester, UK, 2008; p. 304.

55. Lilburne, L.; Tarantola, S. Sensitivity analysis of spatial models. Int. J. Geogr. Inf. Sci. 2009, 23, 151-168.

56. Homma, T.; Saltelli, A. Importance measures in global sensitivity analysis of nonlinear models. Reliab. Eng. Syst. Saf. 1996, 52, 1-17.

57. Saltelli, A.; Annoni, P.; Azzini, I.; Campolongo, F.; Ratto, M.; Tarantola, S. Variance based sensitivity analysis of model output. Design and estimator for the total sensitivity index. Comput. Phys. Commun. 2010, 181, 259-270.

58. Ligmann-Zielinska, A.; Sun, L. Applying time dependent variance-based global sensitivity analysis to represent the dynamics of an agent-based model of land use change. Int. J. Geogr. Inf. Sci. 2010, 24, 1829-1850.

59. Tarde, G. The Laws of Imitation; The Mershon Company Press: Rahway, NJ, USA, 1903.

60. Ryan, B.; Gross, N.C. The diffusion of hybrid seed corn in two Iowa communities. R. Soc. 1943, 8 , $15-24$.

61. Rogers, E.M. Diffusion of Innovations; Free Press: New York, NY, USA, 2003. 
62. Heong, K.L.; Escalada, M.M. A comparative analysis of pest management practices of rice farmers in Asia. In Pest Management of Rice Farmers in Asia; Heong, K.L., Escalada, M.M., Eds.; International Rice Research Institute: Los Baños, Philippines, 1997; pp. 227-242.

63. Borron, S. Building Resilience for an Unpredictable Future: How Organic Agriculture Can Help Farmers Adapt to Climate Change; United Nations Food and Agriculture Organization: Rome, Italy, 2006.

64. Bankes, S. Exploratory modeling for policy analysis. Oper. Res. 1993, 41, 435-449.

65. Weaver, C.P.; Lempert, R.J.; Brown, C.; Hall, J.A.; Revell, D.; Sarewitz, D. Improving the contribution of climate model information to decision making: The value and demands of robust decision frameworks. Wiley Interdiscip. Rev.: Clim. Change 2013, 4, 39-60.

66. Bankes, S.; Lempert, R.; Popper, S. Making computational social science effective: Epistemology, methodology, and technology. Soc. Sci. Comput. Rev. 2002, 20, 377-388.

67. Downey, E.; Brill, J. The use of optimization models in public-sector planning. Manag. Sci. 1979, 25, 413-422.

68. Meadows, D. Thinking in Systems: A Primer; Chelsea Green: White River Junction, VT, USA, 2008.

69. Peck, S.L. Simulation as experiment: A philosophical reassessment for biological modeling. Trends Ecol. Evol. 2004, 19, 530-534.

(C) 2015 by the authors; licensee MDPI, Basel, Switzerland. This article is an open access article distributed under the terms and conditions of the Creative Commons Attribution license (http://creativecommons.org/licenses/by/4.0/). 